\title{
Open data formats in building information modeling
}

\author{
Olga Baranova* $^{*}$
}

Moscow State University of Civil Engineering, Yaroslavskoe shosse, 26, Moscow, 129337, Russia

\begin{abstract}
Building Information Modeling (BIM) technology is one of the most actively developing approaches to the digital representation of the design of buildings and structures, which makes it possible to ensure the relationship of both geometric and functional characteristics of a designed object. The organization of information exchange within the framework of the development of IM during various stages of the life cycle is a rather difficult task, since the historical development of software products used for the design of IM elements has led to the use of various data presentation formats for solving specialized design and calculation problems. In the documents analyzed in the work, two formats with an open specification - IFC and XML - are mentioned as a means of information exchange in the development of IM. In addition to the undoubted advantages of using the IFC using the EXPRESS data specification language as a means of ensuring the interoperability of information systems, there are currently difficulties with the practical application of this format in information modeling, including for organizing joint work. XML-schema can be used as an alternative to the representation of IM in the IFC for organizing data exchange between various information systems, including when implementing joint work on IM through web applications. The use of alternative to EXPRESS schemes for the definition of IM data makes it possible to simplify the organization of information transfer between participants in the information exchange, as well as to unify the presentation of design information.
\end{abstract}

\section{Introduction}

Building Information Modeling (BIM) technology is one of the most actively developing approaches to the digital representation of the design of buildings and structures, which makes it possible to ensure the relationship of both geometric and functional characteristics of a designed object. This approach allows you to provide a sufficiently high level of detail of the project, and also makes it possible to exchange 3D models of buildings in the early stages of design to ensure the most efficient work. Throughout the life cycle of a building (LC), the information model (IM) is constantly being improved, filled with new data, going from a conceptual model to a digital analogue of a building, which, in addition to geometric information, includes temporal (4D) and cost (5D) characteristics, information about the

\footnotetext{
* Corresponding author: ombaranova@mail.ru
} 
actual the condition of the facility for maintenance during operation (6D), cost control during the life cycle of the building (7D) [1-10].

The organization of information exchange within the framework of the development of IM during various stages of the life cycle is a rather difficult task, since the historical development of software products used for the design of MI elements has led to the use of various data presentation formats for solving specialized design and calculation problems. At the same time, it is obvious that, for example, architects and designers in the process of forming an IM should jointly coordinate the design decisions they make. Ensuring the interaction of various information systems is possible as a result of achieving their integration or interoperability [11]. The task of achieving interoperability of various information systems is complicated by the fact that they are based, as a rule, on the use of various proprietary software products to create elements of information technology related to different disciplines. Direct conversion between several proprietary data presentation formats is either impossible in most cases, or leads to significant data distortion. One of the possible ways to solve the problem of data exchange between proprietary software products in order to create a single IM is to use a neutral open data format [12-13]. The ideology of open (non-commercial) data formats, without requiring significant changes either in the algorithm of operation or in the structure of the code of software products, allows them to be used as a kind of frontier environment, the main role of which is to provide such a presentation of the IM data, which could be adequately perceived by various software products specialized in the tasks of different disciplines of the construction industry in order to ensure interaction between them. At the same time, the number of open data formats used to ensure the interaction of information systems should not be large, and the formats themselves should be unambiguously perceived in all software environments that are significant for the formation of IM.

\section{Methods}

As part of the work, legislative, regulatory and reference information, scientific developments, methods and publications on the issue of ensuring the integration and interoperability of information systems, including the definition of requirements for IM data formats, have been analyzed. In GOST R 55062-2012 "Information technology. Industrial automation systems and their integration. Interoperability. Basic Provisions "the importance of interoperability for ensuring the interaction of systems is indicated, the profile of interoperability and the main stages of ensuring interoperability are determined. In SP 331.1325800.2017 "Information modeling in construction. Rules of exchange between information models of objects and models used in software systems", rules and requirements for interoperability at various levels are given. In this document, it is recommended to use the open IFC format (ISO 16739 - Industry Foundation Classes (IFC) for data sharing in the construction and facility management industries) to organize information exchange at the software and technical level. The Decree of the Government of the Russian Federation of September 15, 2020 No. 1431 defines the rules for the formation and maintenance of an information model (IM) of a capital construction object, as well as the composition of information, documents and materials included in the information model of a capital construction object and presented in the form of electronic documents, and requirements for the formats of these electronic documents. The document defines IFC or another open specification data format as the 3D model data format. At the same time, there is a rather important remark: "Before the approval by the Ministry of Construction and Housing and Utilities of the Russian Federation, the scheme to be used for generating electronic documents in the form of files in XML format." The order of the Moscow City Committee on Pricing Policy in Construction and State Expertise of Projects dated 09.09.2020 No. MKE-OD / 20-45 defines the requirements for information models of 
capital construction facilities, including general requirements for digital information models of buildings for passing the examination when using information modeling technologies. In particular, it is prescribed to use the IFC format of a version not lower than IFC4 as a format for providing a digital information model. Thus, the analyzed documents mention two formats with an open specification - IFC and XML - as a means of information exchange in the development of I.M.

Autodesk Revit (Autodesk, Inc., USA) and Renga (Renga Software, Russia) were used as software products for the study of the IFC format for organizing information exchange in the development of IM. As part of the work, an analysis of the degree of distribution of requests on IFC and XML topics was carried out., Google Trends service was used as an analysis tool.

Results. As part of the study of the capabilities of the IFC format using the EXPRESS data specification language for organizing the exchange of information in the development of IM, the IM of buildings created in the Autodesk Revit software product (Autodesk, Inc., USA) was exported to the IFC format (version IFC4). Subsequently, IMs in IFC format were imported into Autodesk Revit (Autodesk, Inc., USA) and Renga (Renga Software, Russia) software products.

The original first IM, created in Autodesk Revit (Autodesk, Inc., USA), is shown in Fig. 1.

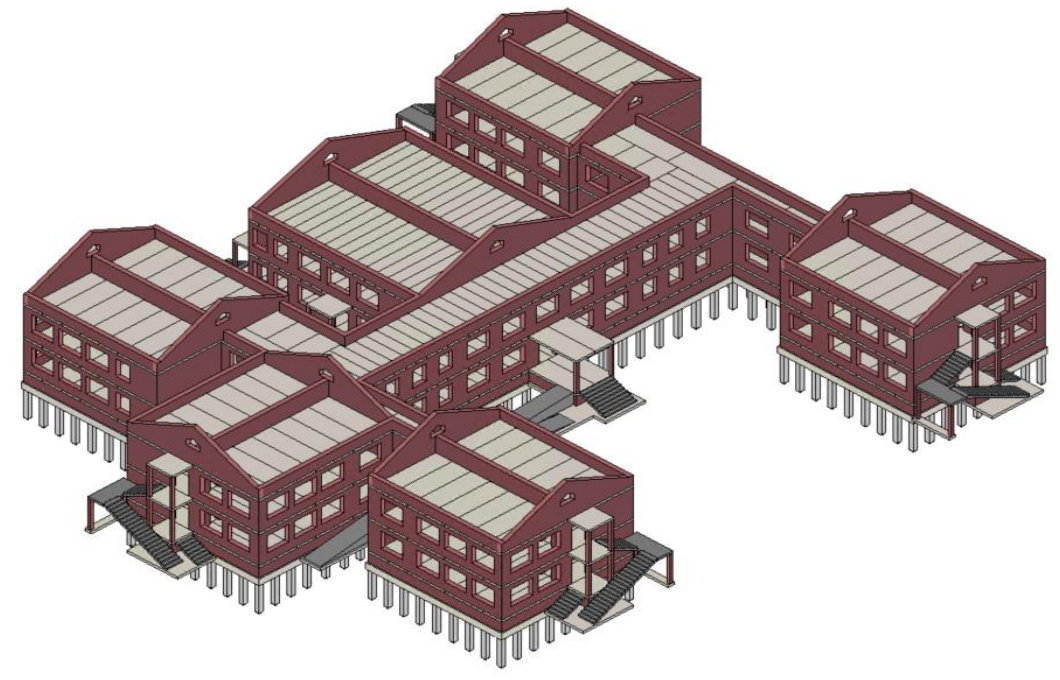

Fig. 1. The original first IM created in Autodesk Revit (Autodesk, Inc., USA).

IM after importing a file in IFC format into the Autodesk Revit software environment (Autodesk, Inc., USA) is shown in Fig. 2. 


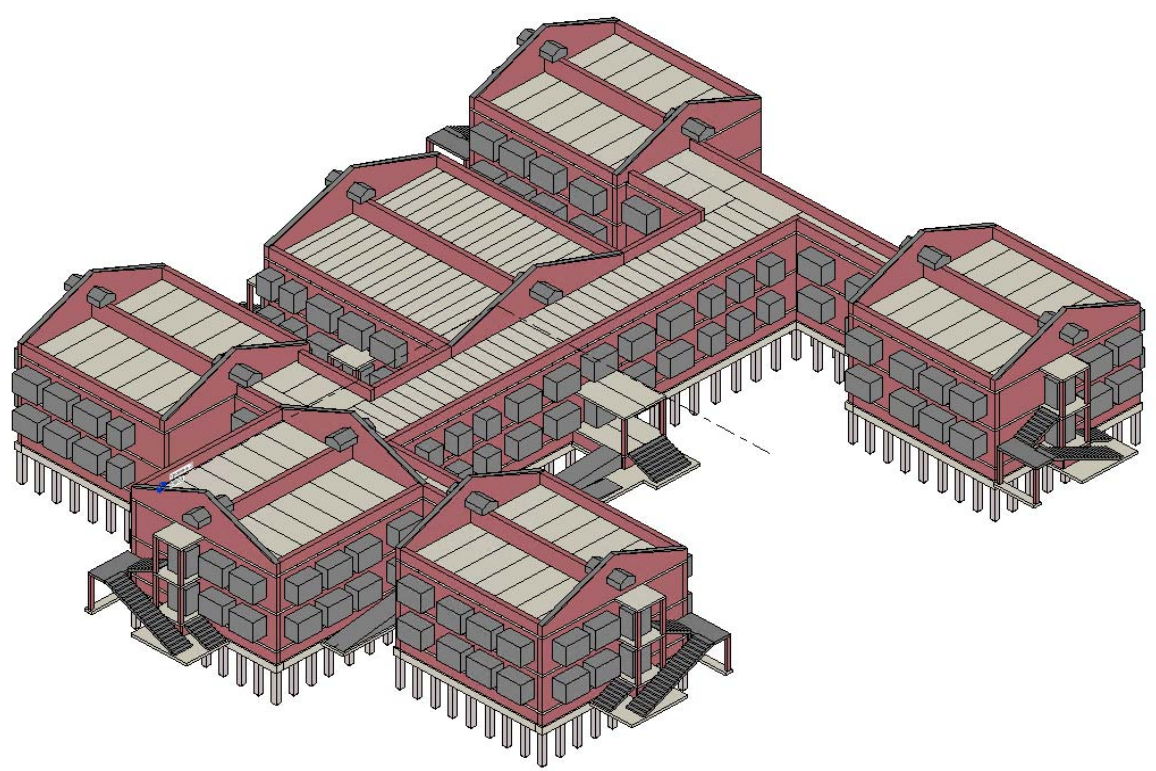

Fig. 2. The first IM, created in Autodesk Revit (Autodesk, Inc., USA), after importing a file in IFC format into the Autodesk Revit software environment (Autodesk, Inc., USA).

After importing from the IFC format, when using the same software product for exporting to the IFC format and importing from it, the violation of the geometric characteristics of the IM is obvious, which, first of all, was reflected in the distortion of window, door and other openings. In addition, for the imported IM it is impossible to change the type and geometry of the IM elements, that is, there is no possibility of editing the IM elements.

On the contrary, when exporting another IM in the IFC format using the Autodesk Revit software product (Autodesk, Inc., USA) and importing the resulting file in IFC format into the Renga software product (Renga Software, Russia), no significant IM distortions occurred (Fig. 3,4).

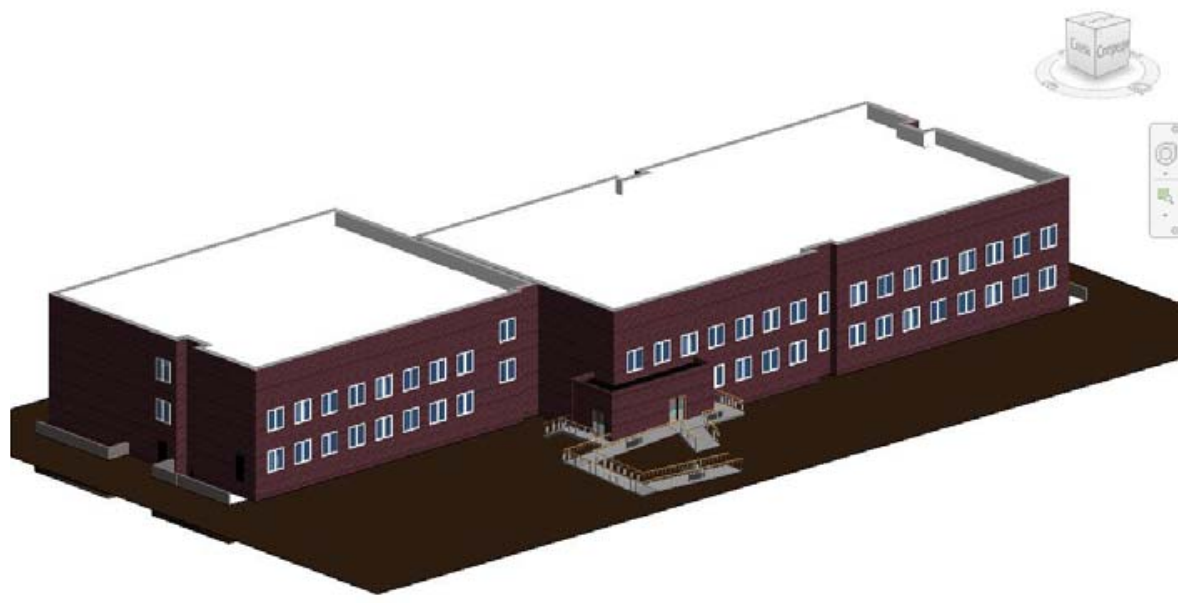

Fig. 3. The original second IM, created in Autodesk Revit (Autodesk, Inc., USA). 


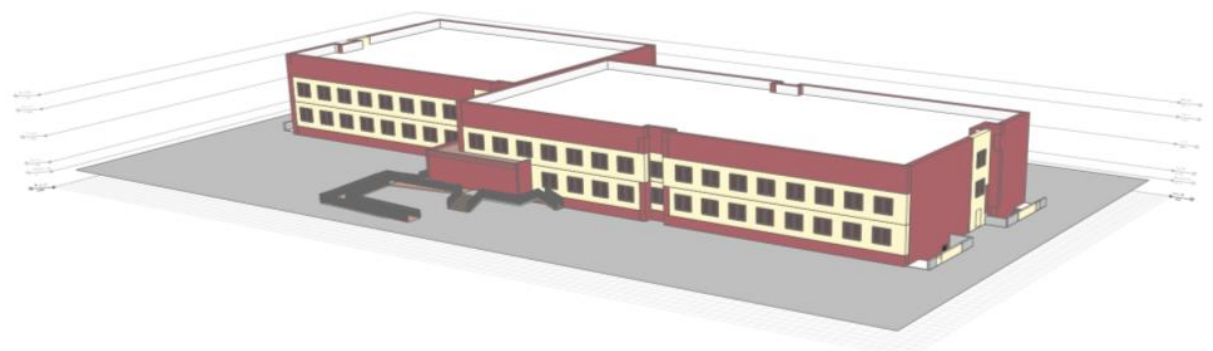

Fig. 4. The second IM, created in Autodesk Revit (Autodesk, Inc., USA), after importing a file in IFC format into the Renga software environment (Renga Software, Russia).

The geometrical characteristics of the MI are sufficiently preserved, the possibility of editing the elements of the MI is available.

The study shows that, in addition to the undoubted advantages of using the IFC format using the EXPRESS data specification language as a means of ensuring the interoperability of information systems at the present time, such as the openness of the IFC format, which allows software developers to embed tools for converting data into the IFC format and back from IFC in the format of the application into its own software products, the vastness of the element modeling language, the extensibility of the IFC scheme to display a large number of new types and properties of elements, the possibility of wide coverage and ensuring the interaction of various disciplines related to the design, construction and operation of a capital construction object throughout its life cycle, there are difficulties with the practical application of this format in information modeling, including for organizing joint work. First of all, as it follows from the study, the complexity arises in the presence of various approaches to converting data into the IFC format and back in the currently most common information modeling software products, since software developers quite often do not use the full potential of IFC specifications. they use what can be relatively easily correlated with the key features of proprietary software products. Achievement of universality and extensibility of the IFC format modeling language using the EXPRESS data specification language leads to the complication of its construction, the variability of the description of elements complicates the unambiguous interpretation of IFC data when imported into proprietary software products, and the use of a simple text description for modeling objects leads to the fact that files in IFC format are quite large. These difficulties are not insurmountable, but they seriously affect the spread of the IFC format using the EXPRESS data specification language as a means of ensuring the interoperability of information systems.

In this regard, the desire to find an alternative to the use of the IFC format using the EXPRESS data specification language among the open specification formats seems justified, which would have a wide audience reach, flexibility of possible applications and relative ease of implementation. This approach could be using XML schemas.

XML-schema can be used as an alternative to the representation of IM in the IFC format for organizing data exchange between various information systems, including when implementing joint work on IM through web applications. The extended markup language of the building information model BIMXML can be used as a tool for describing IM elements, however, it should be borne in mind that currently the use of BIMXML involves the formation of a simplified, in comparison with IFC, representation of IM elements. Another option for generating XML schemas is to use the XML Schema Definition Language (XSD) in accordance with the W3C XML Schema standard, where the XML 
schema definition is derived from the EXPRESS schema, taking into account the mapping rules defined in ISO 10303-28. The latter option is more common today.

Using the Google Trends tool, we analyzed the distribution of queries on IFC and XML topics across regions of the world over the past five years in the field of real estate.

Additionally, a comparison was made of the distribution of queries on IFC and XML topics across the world over the past five years in the field of real estate (Fig. 5). Obviously, in this area of activity in the regions of the world, XML queries prevail.
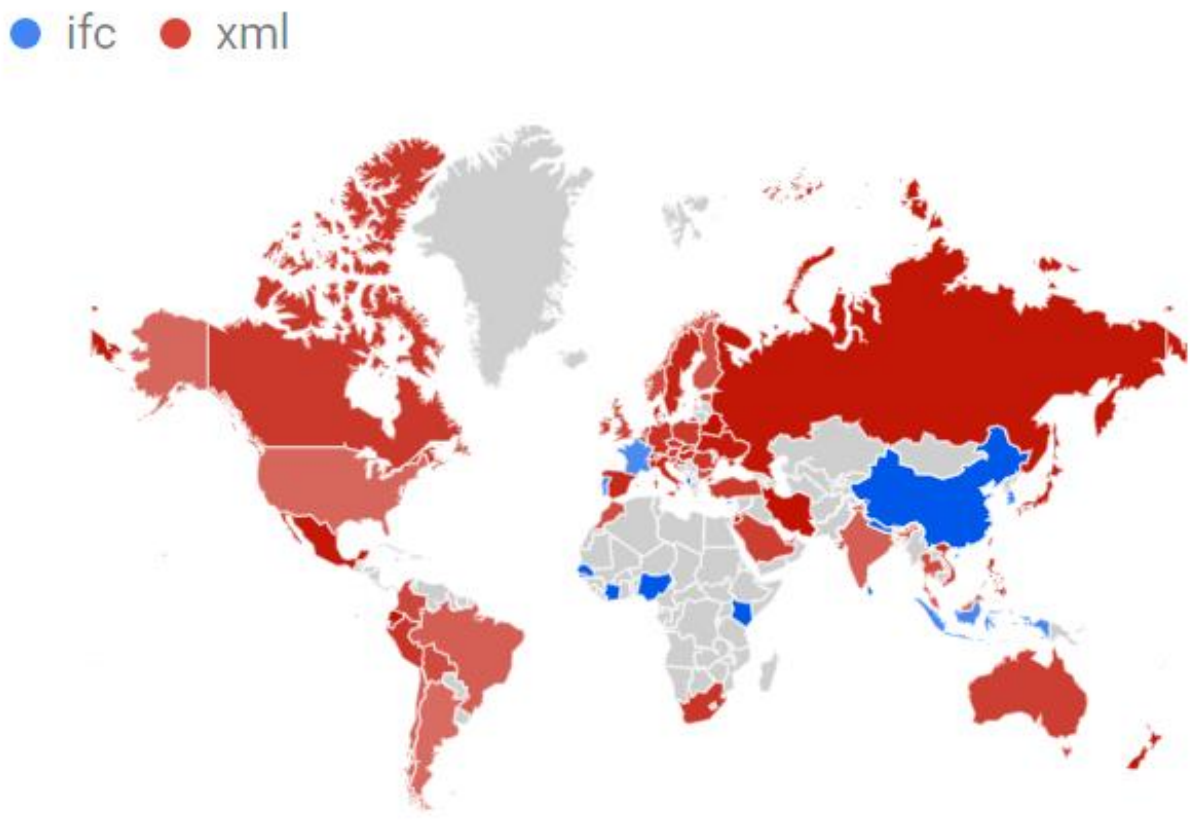

Fig. 5. Comparison of the spread of queries on IFC and XML topics by region of the world over the past five years in real estate.

Taking into account the requirements of the legal framework, it is advisable to use XML schemas as a means of organizing the exchange of electronic documents at all stages of the life cycle of a capital construction object, in particular, when transferring information to the state information system for ensuring state activities (GISOGD), as well as when interacting with others. state information systems [14-19].

\section{Discussion}

Despite the obvious advantages of using the IFC format using the EXPRESS data specification language for organizing data exchange during the formation of IMs for capital construction objects, it should be noted that there are some objective inconveniences associated with the absence of $100 \%$ IM identity after export to IFC in one software product and import from IFC to another software product due to the presence of objective differences in the representation of the structural elements of information technology in various information systems [20].

The use of alternative to EXPRESS schemes for the definition of IM data makes it possible to simplify the organization of information transfer between information exchange participants, as well as to unify the presentation of design information. 


\section{Conclusions}

On the basis of the stated positions, it seems expedient to use the definition of the data schema of an IM not only using the EXPRESS data specification language, but the XML schema definition language, which will allow more flexible organization of the space for joint work in the formation of the IM, as well as interact with state information systems.

\section{References}

1. A. Ginzburg, L. Shilov, L. Shilova. The methodology of storing the information model of building structures at various stages of the life cycle. Journal of physics: conference series. International Scientific Conference on Modelling and Methods of Structural Analysis 2019, MMSA 2019 (2020)

2. A.V. Ginzburg/ Building life cycle information modelling. Promyshlennoe i grazhdanskoe stroitelstvo [Industrial and Civil Engineering], 9, 61-65 (2016)

3. A. Volkov. General information models of intelligent building control systems: basic concepts, determination and the reasoning. Applied Mechanics and Materials, vol. 838841, 2973-2976 (2014)

4. A. Volkov, V. Chulkov, R. Kazaryan, R. Gazaryan. Cycle reorganization as model of dynamics change and development norm in every living and artificial beings. Applied Mechanics and Materials, vol. 584-586, 2685-2688 (2014)

5. V.V. Talapov. BIM Technology. Essence and features of building information modeling introduction. DMK Press, Moscow (2015)

6. A. Ginzburg. LE IM: living environment information modelling. 2018 INTERNATIONAL SCIENTIFIC CONFERENCE ENVIRONMENTAL SCIENCE FOR CONSTRUCTION INDUSTRY, ESCI (2018)

7. A.V. Ginzburg. Building life cycle information modelling. Promyshlennoe i grazhdanskoe stroitelstvo [Industrial and Civil Engineering], 2016, 9, 61-65.

8. S. Azhar et al. Building information modeling (BIM): now and beyond. Australasian Journal of Construction Economics Building. 12 (4). 15-28. (2012)

9. N.A. GARYAEV, F. AYOUB. Towards building information modelling for diagnosis, assessment and rehabilitation automation for existing buildings. Journal of physics: conference series. International Scientific Conference on Modelling and Methods of Structural Analysis 2019, MMSA 2019 (2020)

10. M. Andreani, S. Bertagni, C. Biagini, F. Mallo. 7D BIM for sustainability assessment in design processes: a case study of design of alternatives in severe climate and heavy use conditions. Architecture and Engineering. 4. 3-12. 10.23968/2500-0055-2019-4-23-12. (2019)

11. A.V. Ginzburg, E.N. Kulikova, A.S. Pavlov, M.S. Vainshtein. Interoperability in construction design by means of information modeling technologies. The Eurasian Scientific Journal, [online] 6(11) (2019)

12. A. Katzenbach, S. Handschuh, S. Vettermann. JT format (ISO 14306) and AP 242 (ISO 10303): The step to the next generation collaborative product creation. IFIP Advances in Information and Communication Technology. Springer, Berlin, Heidelberg, 41-52 (2013)

13. K.Yu. Losev. The approach to CDE design information support within a construction object life cycle. The Eurasian Scientific Journal, [online] 6(10) (2018)

14. A.A. Volkov, V.M. Roytman, L.A. Shilova Model of stability of life support systems in emergency situations. International Journal of Applied Engineering Research. 11(3), 1666-1669 (2016)

15. A. Volkov, A. Sedov, P. Chelyshkov, E. Kulikova. Modeling the thermal comfort of internal building spaces in hospital. Applied Mechanics and Materials. 584-586:753$756(2014)$ 
16. A. Volkov, P. Chelyshkov, Y. Grossman, A. Khromenkova. BIM cost analysis of transport infrastructure projects. IOP Conference Series: Earth and Environmental Science, 90:012203 (2017)

17. A. Volkov, A. Sedov, P. Chelyshkov. Modelling the thermal comfort of internal building spaces in social buildings. Procedia Engineering. 91:362-367 (2014)

18. A. Volkov, A. Sedov, P. Chelyshkov, E. Kulikova Modeling the thermal comfort of internal building spaces in kindergarten. Applied Mechanics and Material. 584586:757-760 (2014)

19. S.A. Volkov, T.V. Khripko. Using XML schemas to structure information models of capital construction facilities. Vestnik MGSU [Monthly Journal on Construction and Architecture]. 15(11):1570-1583 (2020)

20. Ch. Eastman. The Future of IFC: Rationale and Design of a SEM IFC Layer, Materials from IDDS Workshop, 6, Vol 10 (2018) 